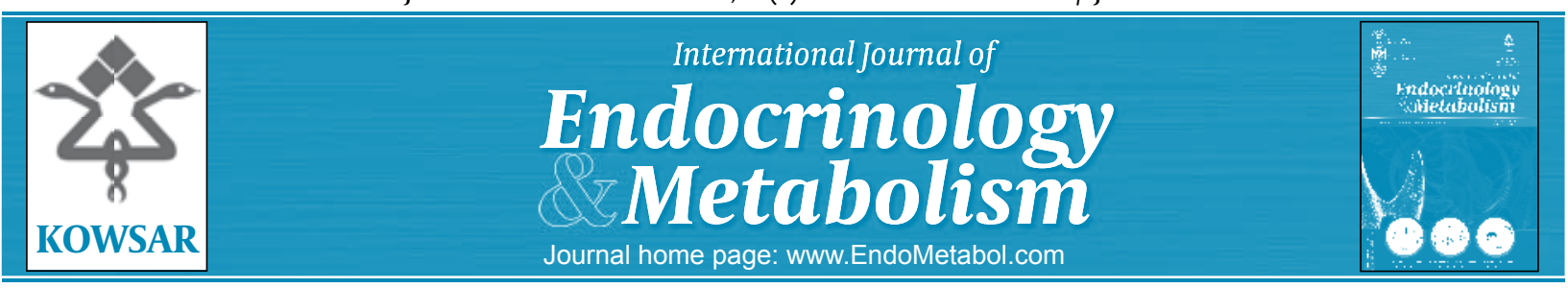

\title{
Investigation of Association Between TLR4 Gene Polymorphisms and Osteoporosis in Postmenauposal Turkish Women
}

\author{
Zehra Sema Ozkan ${ }^{1 *}$, Derya Deveci ${ }^{2}$, Huseyin Yuce ${ }^{2}$ \\ ${ }^{1}$ Kecioren Education and Research Hospital, Department of Obstetric and Gynecology, Ankara, Turkey \\ ${ }^{2}$ Firat University School of Medicine, Department of Medical Biology, Elazig, Turkey
}

Article type:

Original Article

Article history:

Received: 06 Oct 2011

Accepted: 05 Dec 2011

Keywords:

Bone Mineral Density

Cytokine

Inflammation TLR4
A R T I C L E I N F O

Revised: 30 Nov 2011

Polymorphism

Postmenopausal Osteoporosis

\begin{abstract}
A B S T R A C T
Background: Postmenopausal osteoporosis is a systemic bone disease that is characterized by accelerated bone loss after menopause and an increased risk of fractures. The immune system and cytokines regulate bone metabolism. Toll-like receptors (TLRs) play an important role in the induction and regulation of the innate immune system and adaptive immune responses.

Objectives: To investigate the association between TLR4 gene polymorphisms and bone mineral density (BMD) in postmenopausal osteoporotic (OP) and nonosteoporotic (NOP) Turkish women.

Patients and Methods: The study population consisted of 178 OP and 178 NOP Turkish women. BMDs were obtained by dual-energy X-ray absorptiometry. Two single-nucleotide polymorphisms (SNPs) of the TLR4 gene (Asp299Gly and Thr399Ile) were examined by polymerase chain reaction-restriction fragment length polymorphism. The frequency of polymorphisms and the possible relationships between genotypes and BMD were the main outcome measures.

Results: Lumbar BMD of OP women was significantly lower than in NOP women $(P=$ 0.04), but total hip BMD and Z scores did not differ. The frequency of the Asp299Gly and Thr399Ile polymorphisms in our population was $18 \%$ and $15 \%$, respectively. There was no significant difference in the frequency of TLR4 gene (Asp299Gly and Thr399Ile) polymorphisms between OP and NOP women, but carriers of heterozygous genotypes had lower BMDs $(P<0.01$ and $P<0.01)$.

Conclusions: We observed lower BMDs in carriers of heterozygous genotypes of polymorphisms than homozygous mutant genotypes. With our limited population, no firm conclusions can be drawn as to what extent low bone mineral density is associated with these heterozygous genotypes, and further studies are needed to analyze our results.
\end{abstract}

Copyright ๑2012 Kowsar M. P. Co. All rights reserved.

- Implication for health policy/practice/research/medical education:

This study gives a new vision about genetic basis of osteoporosis which has multifactorial etiology. New pharmacological approaches could be improved for treatment and prevention of osteoporosis.

- Please cite this paper as:

Ozkan ZS, Devici D, Yuce H. Investigation of Association Between TLR4 Gene Polymorphisms and Osteoporosis in Postmenauposal Turkish Women. Int J Endocrinol Metab. 2012;10(1): 418-22. DOI: 10.5812/ijem.3724

* Corresponding author: Zehra Sema Ozkan, Firat Universitesi Hastanesi Kadin Dogum Anabilim Dali, 23119, Elazig, Turkey. Tel: +90-5053983219, Fax:+90-4242388096, E-mail: zehrasema@yahoo.com

DOI:10.5812/ijem.3724

1. Background

Postmenopausal osteoporosis is a systemic bone disease that is characterized by accelerated bone loss after menopause and increased risk of fractures. Estrogen deficiency during menopause is one of the major underlying factors of osteoporosis in women (1). Estrogen deficiency is associated with accelerated osteoblast 
apoptosis and increased production of pro-inflammatory cytokines (2). Exposure of bone cultures to supernatants from activated leukocytes is associated with induced osteoclast formation (2-4). In the molecular pathogenesis of osteoporosis, inflammatory cytokines play a key role in osteoclast interactions during bone turnover (4). The relationship between bone turnover and inflammatory cytokines, their receptors, and intracellular signaling pathways has been recently investigated with regard to osteoporosis (5-8).

Toll-like receptors (TLRs) are pattern recognition receptors (PRRs) and initiate cellular signaling pathways to activate immune response genes, including inflammatory cytokines (9). Ten human TLRs have been identified (5). Each TLR recognizes specific ligands, including lipoproteins, lipoteichoic acid, and zymosan by TLR2; dsRNA by TLR3; lipopolysaccharide (LPS) by TLR4; flagellin by TLR5; ssRNA by TLR7/8; and CPG DNA by TLR9. Twenty-nine single-nucleotide polymorphisms (SNPs) have been identified in the human TLR4 gene (10).

TLR4, a member of the TLR family, is expressed on cardiomyocytes, macrophages, airway epithelium, and endothelial and smooth muscle cells $(11,12)$ and recognizes endogenous ligands, such as fibronectin and several heat shock proteins (HSPs). Two nonsynonymous and common gene polymorphisms in the extracellular domain of TLR4, Asp299Gly and Thr399Ile, have been suggested to alter its function and cause hyporesponsiveness to LPS in human alveolar macrophages and airway epithelial cells (12). Individuals who carry the Asp299Gly allele of TLR4 have lower levels of proinflammatory cytokines, acute-phase reactants, and soluble adhesion molecules, such as interleukin 6 and fibrinogen (13). The reduced but chronic expression of these cytokines causes chronic inflammation, which leads to the transformation of macrophages into osteoclasts over long periods (14).

The osteoclast/osteoblast balance is a distinctive marker of bone turnover and osteoporosis. Postmenopausal osteoporosis is a multifactorial condition that we examined with regard to the possible interaction between BMD and TLR4 gene polymorphisms in postmenopausal Turkish women.

\section{Patients and Methods}

\subsection{Study Population}

We conducted a multicenter, prospective, controlled study with Firat University Hospital, Elazig and Kecioren Education and Research Hospital, Ankara, Turkey. The protocol of this study was approved by the ethics committee of Firat University Hospital. A total of 356 postmenopausal women-178 osteoporotic (OP) (T score on BMD measurement $<-2.5 \mathrm{SD}$ ) and 178 nonosteoporotic women (NOP) ( $\mathrm{T}$ score on BMD measurement $>$ -1.0 SD) -who visited the menopause out-patient clinic of Keciören Education and Research Hospital and
Nuclear Medicine Clinic of Firat University Hospital between May 2009 and November 2009 were included in our study. Demographics and lifestyle factors, including menopausal period, smoking history, average daily alcohol consumption, and dietary calcium intake, were recorded through lifestyle and food frequency questionnaires that were completed at baseline. Body weight and height were measured at baseline, and body mass index (BMI) was calculated. A detailed medical history of the subjects was obtained through health questionnaires. Blood fasting glucose and hepatic and renal functions were measured. Women who had undergone an ovariectomy or who had hepatic or renal disease, diabetes mellitus, or other endocrine diseases were excluded from this study. None of the subjects had received any medication that is known to affect bone metabolism (such as glucocorticoids, thyroxin, antiepileptics, bisphosphonates, calcitonin, and hormone replacement therapy for more than 3 months). Those who had conditions that were known to affect BMD were excluded from the study. All interviews were conducted by trained interviewers. Informed consent was obtained from all subjects at the time of blood sampling.

\subsection{BMD Measurement}

Areal BMD (g/cm2) at L2-L4 of the lumbar spine and total hip was measured by dual energy X-ray absorptiometry (DEXA). Densitometers were calibrated daily. The coefficient of variation for DEXA instrumentation was $0.52 \%$. OP and NOP groups consisted of women whose T scores at the lumbar spine by DEXA were lower than -2.5 and higher than -1 , respectively.

\subsection{Genotyping}

Genomic DNA from patients and controls was extracted from peripheral white blood cells using the Wizard Genomic DNA Extraction Kit (Promega, USA), per the manufacturer's instructions.

\subsection{PCR}

Two polymorphisms of the TLR4 gene (Asp299Gly and Thr399Ile) were examined in 178 OP and 178 NOP women using polymerase chain reaction-restriction fragment length polymorphism (PCR-RFLP). Detection of TLR4 polymorphisms was performed per Lorenz et al. (15). The PCR primers for Asp299Gly and Thr399Ile were as follows:

TLR4Asp299Gly Forward: 5'GATTAGCATACTTAGACTACTACCTCCATG

Reverse: 5'GATCAACTTCTGAAAAAGCATTCCCAC

TLR4 Thr399Ile Forward: 5'GGTTGCTGTTCTCAAAGTGATTTTGGGAGAA

Reverse: 5'CCTGAAGACTGGAGAGTGAGTTAAATGCT

The program comprised 30 cycles of the following: $95^{\circ} \mathrm{C}$ for $4 \mathrm{~min}, 95^{\circ} \mathrm{C}$ for $30 \mathrm{~s}, 55^{\circ} \mathrm{C}$ for $30 \mathrm{~s}$, and $72^{\circ} \mathrm{C}$ for 
$30 \mathrm{~s}$. The amplicons were cleaved with NcoI (Asp299Gly) and HinfI (Thr399Ile), respectively. Digested products were separated on a $3 \%$ agarose gel.

\subsection{Statistical Analysis}

Statistical analysis was performed using SPSS 12.0 (Inc., Chicago, Illinois, USA). Results were expressed as mean and standard deviation or number and percentage, as appropriate. Differences between means were analyzed by student's t-test and Mann-Whitney U-test according to the distribution of data. The significance of differences between groups was assessed by chi-squared test or Fisher's exact test for categorical variables, where applicable. Hardy-Weinberg equilibrium was tested for each genotyped SNP using $\chi 2$ statistics. Stepwise regression was used to analyze lumbar spine and total hip BMD, using BMI, age, smoking, and alcohol intake to identify significant covariates of BMD. ANOVA was performed to analyze the lumbar spine and total hip BMD of each SNP genotype. P values $<0.05$ were considered significant for all analyses.

\section{Results}

This study was designed to detect any association between BMD and the Asp299Gly and Thr399Ile TLR4 polymorphisms in postmenopausal OP and NOP Turkish women. For both groups, the menopausal period was at least 5 years. The demographics of the women are presented in Table 1. BMI and age were covariates that approached statistical significance on fitting BMD in the regression model. Genotype frequencies of Asp299Gly for OP and NOP women are shown in Table 2. The allelic frequencies of Asp299Gly in OP women were 87\% A allele and $13 \% \mathrm{G}$ allele versus $90 \% \mathrm{~A}$ allele and $10 \% \mathrm{G}$ allele in NOP women.

The genotype frequencies of Thr399Ile for the groups

\begin{tabular}{|c|c|c|c|}
\hline Characteristics $^{\mathrm{b}}$ & $\begin{array}{l}\text { OP }^{a} \\
(n: 178)\end{array}$ & $\begin{array}{l}\text { NOP }^{a} \\
(n: 178)\end{array}$ & $P$ value \\
\hline Age, y & $57 \pm 7$ & $57 \pm 6$ & 0.89 \\
\hline Weight, kg & $70 \pm 13$ & $71 \pm 14$ & 0.39 \\
\hline Height, cm & $156 \pm 6$ & $154 \pm 7$ & $<0.01$ \\
\hline $\mathrm{BMI}^{\mathrm{a}}, \mathrm{kg} / \mathrm{m}^{2}$ & $29 \pm 5$ & $30 \pm 5$ & 0.02 \\
\hline Lumbar spine BMD ${ }^{\mathrm{a}}, \mathrm{g} / \mathrm{cm}^{2}$ & $0.969 \pm 0.199$ & $1.023 \pm 0.278$ & 0.04 \\
\hline Total hip BMD, $\mathrm{g} / \mathrm{cm}^{2}$ & $0.977 \pm 0.146$ & $1.008 \pm 0.209$ & 0.11 \\
\hline Lumbar spine Z score & $-0.7 \pm 1.5$ & $0.5 \pm 2.0$ & 0.26 \\
\hline Total hip Z score & $-0.3 \pm 1.2$ & $-0.1 \pm 1.5$ & 0.18 \\
\hline
\end{tabular}

a Abbrevietions: OP, Osteoporotic group; NOP, Nonosteoporotic group; BMI, Body mass index; BMD, Bone mineral density

${ }^{\mathrm{b}}$ Values are expressed as Mean $\pm \mathrm{SD}$

are shown in Table 2. The allele frequencies of this polymorphism in OP and NOP women were $88 \% \mathrm{C}$ allele and $12 \% \mathrm{~T}$ allele versus $93 \% \mathrm{C}$ allele and $7 \% \mathrm{~T}$ allele, respectively (Table 2). We did not detect any significant difference

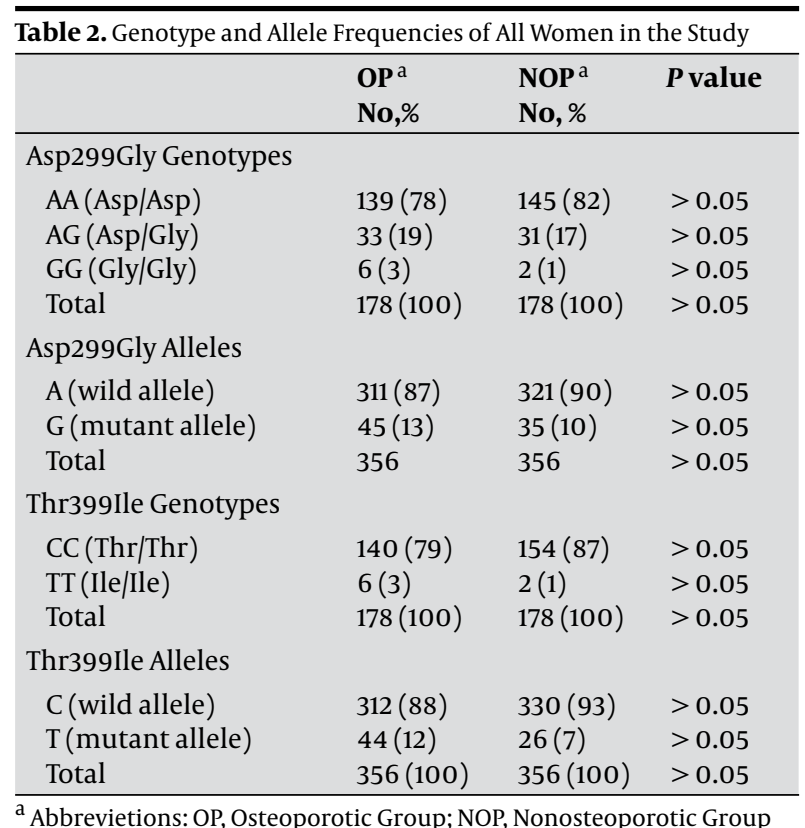

in genotype or allele distribution for the 2 polymorphisms between groups. Homozygous mutant genotypes of these polymorphisms were rare in our small population. The frequency of alleles approximated Hardy-Weinberg equilibrium $\left(\chi_{2}=2.4 P=0.6\right)$.

We examined the difference in lumbar spine and total hip BMD between genotypes (Table 3). The heterozygous genotypes (AG and CT) had significantly lower BMDs than wild-type genotypes. There was no significant difference in BMI between genotypes in the entire study population (Table 3).

\section{Discussion}

Postmenopausal osteoporosis is a multifactorial systemic bone disease, and estrogen deficiency is one of the major underlying factors of osteoporosis in women (1). Human and animal experiments have implicated inflammatory cytokines as primary mediators of the accelerated bone loss during menopause (16). Estrogen deficiency is associated with increased production of pro-inflammatory cytokines, and exposure of bone cultures to supernatants from activated leukocytes is associated with induced osteoclast formation (2-4). Further, in bone, estrogen deficiency is linked to accelerated osteoblast apoptosis and predisposition to osteoporotic fractures (17). The most frequently examined genetic topics of osteoporosis are the immune system, inflammatory cytokines, and their receptors and the mechanism by which osteoblastic and osteoclastic activity is regulated (16-18).TLR4 may participate in the development of osteoporosis, in addition to its well-known function in the immune response, by recognizing endogenous ligands, such as fibronectin and heat shock proteins (HSPs). Many studies in Caucasians suggest that the TLR4 polymorphism Asp299Gly is as- 


\begin{tabular}{|c|c|c|c|c|c|c|}
\hline \multicolumn{7}{|c|}{ Asp299Gly Genotype $^{\text {b }}$} \\
\hline & Lumbar spine $\mathrm{BMD}^{\mathrm{a}}\left(\mathrm{g} / \mathrm{cm}^{2}\right)$ & $P$ value & Total hip BMD $\left(\mathrm{g} / \mathrm{cm}^{2}\right)$ & $P$ value & $\mathrm{BMI}^{\mathrm{a}}\left(\mathrm{kg} / \mathrm{m}^{2}\right)$ & $P$ value \\
\hline Asp/Asp (AA) & $1.015 \pm 0.251$ & 0.010 & $1.005 \pm 0.188$ & 0.019 & $30 \pm 5$ & 0.31 \\
\hline Asp/Gly (AG) & $0.914 \pm 0.176$ & 0.010 & $0.935 \pm 0.125$ & 0.019 & $29 \pm 4$ & 0.31 \\
\hline Gly/Gly (GG) & $0.962 \pm 0.296$ & 0.010 & $1.002 \pm 0.216$ & 0.019 & $28 \pm 2$ & 0.31 \\
\hline \multicolumn{7}{|c|}{ Thr399Ile Genotype $^{\text {b }}$} \\
\hline & Lumbar spine $\mathrm{BMD}^{\mathrm{a}}\left(\mathrm{g} / \mathrm{cm}^{2}\right)$ & $P$ value & Total hip BMD $\left(\mathrm{g} / \mathrm{cm}^{2}\right)$ & Pvalue & $\mathrm{BMI}^{\mathrm{a}}\left(\mathrm{kg} / \mathrm{m}^{2}\right)$ & $P$ value \\
\hline Thr/Thr (CC) & $1.012 \pm 0.250$ & 0.019 & $1.006 \pm 0.186$ & 0.007 & $30 \pm 5$ & 0.21 \\
\hline Thr/Ile (CT) & $0.912 \pm 0.166$ & 0.019 & $0.922 \pm 0.125$ & 0.007 & $28 \pm 5$ & 0.21 \\
\hline Ile/Ile (TT) & $0.963 \pm 0.296$ & 0.019 & $1.003 \pm 0.216$ & 0.007 & $28 \pm 2$ & 0.21 \\
\hline
\end{tabular}

a Abbreviations: BMI, Body mass index; BMD, Bone mineral density

${ }^{\mathrm{b}}$ Values are expressed as Mean $\pm \mathrm{SD}$

sociated with innate immunity-related diseases, such as chronic inflammatory disease and atherosclerosis $(13,19,20)$, but in the Asian population, this polymorphism is rare $(21,22)$. Kim et al. detected the Asp299Gly or Thr399Ile mutations in any of the 225 diabetic and 153 healthy Korean subjects, and the frequency of TLR4 polymorphisms differed between ethnicities in the Asian population; the prevalence of osteoporosis was not discussed in this population (23). In our study, the frequency of both TLR4 polymorphisms was $15 \%$ and $18 \%$ in the Turkish population. We observed a relationship between bone mineral density and heterozygous genotypes of the Asp299Gly and Thr399Ile TLR4 polymorphisms. Women who were carriers of heterozygous genotypes had significantly lower lumbar spine and total hip BMDs than those with homozygous genotypes. We suggest that TLR4 polymorphisms and their effects on gene expression might change bone turn-over against bone formation [BPS1]. Induced macrophage and osteoclast formation by a chronic low-dose inflammatory microenvironment as a result of these polymorphisms in bone tissue might trigger bone loss. We expected to detect a more pronounced effect on bone loss by homozygous mutant genotypes, but we observed higher bone mass in this small population.

In the literature, no study except Santos et al. has examined TLR4 polymorphisms and BMD; thus, we will discuss our theory on the basis of inflammation. Santos et al. reported frequencies of the Asp299Gly and Thr399Ile TLR4 polymorphisms in 227 Chilean elderly women of $4.6 \%$ and $4.4 \%$, respectively, and any association between TLR4 Asp299Gly and bone mineral density was reported for elderly Chilean women; they discussed their results with regard to inflammation, not peak bone mass (24).

Kim et al. reported that HSP60 was higher in postmenopausal women than premenopausal women and that HSP60 significantly reduced osteoblast viability through increased expression of TLR-2 and TLR-4. Also, they found that blocking antibodies to TLR-2 and TLR4 eliminated the effects of HSP60 on apoptosis. HSP60 upregulated the expression of TLR-2 in bone marrowderived macrophages, and pretreatment with a TLR- 2-blocking antibody inhibited HSP60 and cytokineinduced potentiation of osteoclast formation and bone resorption (25). TLR4 and TLR2 become activated through reactive oxygen species and HSPs, and other non-LPS-dependent mechanisms may effect different signatures of genes and proinflammatory mediators (26).

Johnson et al. reported that mutant TLR4 mice have greater bone mineral content $(P<0.001)$ and larger bones $(P<0.001$, as measured by bone area) than wildtype mice with the same genetic background-differences that increased with age. The mutant mice (loss of TLR4 function) had significantly higher bone mineral density $(P<0.001)$, and this difference increased with age $(P<0.001)(27)$. TLR4 has been believed to function only in inflammation and immunity, profoundly affecting the body shape-effects that increase with age. How mutations in TLR4 effect changes in bone and fat is not known, but bone growth might be regulated by TLR4 on osteoblasts, osteoclasts, or stromal cells-the common precursors of osteoblasts and adipocytes (28).

The Thr399Ile TLR4 polymorphisms cosegregates with Asp299Gly (29). We observed that an allelic mutation of TLR4 gene by TLR4 Asp299Gly and Thr399Ile polymorphisms was related to lower bone mass and that mutant homozygotes had higher bone mass than heterozygotes. Our results are in contrast with Johnson et $a l$., and we hypothesize that the chronic inflammatory microenvironment, as a result of these polymorphisms during menopause, shift macrophage transformation to osteoclastic differentiation, increase the response to inflammatory cytokines in bone tissue, or induce osteoblast apoptosis. We can not examine or discuss the results of mutant homozygotes due to their low frequency in our restricted population. Expanded and different population studies are needed to analyze our results.

\section{Acknowledgments}

We thanks to doctors of Kecioren Education and Research Hospital Departments of Gynecology and Radiology and doctors of Firat University School of Medicine Department of Nuclear Medicine for their provided 
help during our research.

\section{Financial Disclosure}

The authors declare that they have no conflict of interest.

\section{Funding/Support}

This study was supported by Fine University Scientific Reaserch Funding.

\section{References}

1. Consensus development conference: diagnosis, prophylaxis, and treatment of osteoporosis. Am J Med.1993;94 (6) :646-50.

2. Mundy GR. Osteoporosis and inflammation. Nutr Rev. 2007;65 (12 Pt 2) :S147-51.

3. McLean RR. Proinflammatory cytokines and osteoporosis. Curr Osteoporos Rep. 2009;7 (4) :134-9.

4. Rifas L, Weitzmann MN. A novel T cell cytokine, secreted osteoclastogenic factor of activated $\mathrm{T}$ cells, induces osteoclast formation in a RANKL-independent manner. Arthritis Rheum. 2009;60 (11) :3324-35.

5. Bolton CE, Stone MD, Edwards PH, Duckers JM, Evans WD, Shale DJ. Circulating matrix metalloproteinase-9 and osteoporosis in patients with chronic obstructive pulmonary disease. Chron Respir Dis. 2009;6 (2):81-7.

6. Moschen AR, Geiger S, Gerner R, Tilg H. Pre-B cell colony en hancing factor/NAMPT/visfatin and its role in inflammationrelated bone disease. Mutat Res. 2010;690 (1-2):95-101.

7. Nabipour I, Larijani B, Vahdat K, Assadi M, Jafari SM, Ahmadi E, et al. Relationships among serum receptor of nuclear factorkappaB ligand, osteoprotegerin, high-sensitivity C-reactive protein, and bone mineral density in postmenopausal women: osteoimmunity versus osteoinflammatory. Menopause. 2009;16 (5) :950-5.

8. Swanberg M, McGuigan F, Ivaska KK, Gerdhem P, Lerner UH, Bucala $\mathrm{R}$, et al. Polymorphisms in the macrophage migration inhibitory factor gene and bone loss in postmenopausal women. Bone. 2010;47 (2):424-9.

9. Medzhitov R, Janeway C, Jr. Innate immunity. $N$ Engl J Med. 2000;343 (5):338-44

10. Nishimura $M$, Naito $S$. Tissue-specific mRNA expression profiles of human toll-like receptors and related genes. Biol Pharm Bull. 2005;28 (5) :886-92.

11. Akira S, Takeda K, Kaisho T. Toll-like receptors: critical proteins linking innate and acquired immunity. Nat Immunol. 2001;2 (8) :675-80.

12. Raby BA, Klimecki WT, Laprise C, Renaud Y, Faith J, Lemire M, et al. Polymorphisms in toll-like receptor 4 are not associated with asthma or atopy-related phenotypes. Am J Respir Crit Care Med. 2002;166 (11):1449-56

13. Kiechl S, Lorenz E, Reindl M, Wiedermann CJ, Oberhollenzer F, Bonora E, et al. Toll-like receptor 4 polymorphisms and atherogenesis. N Engl J Med. 2002;347 (3) :185-92.

14. Alpay HC, Etem EO, Kaygusuz I, Yuce H, Karlidag T, Keles E, et al. Evaluation of the polymorphism in the Toll-like receptor 4 (TLR4) genes of tympanosclerosis patients. Auris Nasus Larynx. 2010;37 (1) :29-32.

15. Lorenz E, Hallman M, Marttila R, Haataja R, Schwartz DA. Association between the Asp299Gly polymorphisms in the Toll-like receptor 4 and premature births in the Finnish population. Pe diatr Res. 2002;52 (3):373-6.

16. Djaafar S, Pierroz DD, Chicheportiche R, Zheng XX, Ferrari SL, Ferrari-Lacraz S. Inhibition of T cell-dependent and RANKLdependent osteoclastogenic processes associated with high levels of bone mass in interleukin-15 receptor-deficient mice. Arthritis Rheum. 2010;62 (11):3300-10.

17. Bradford PG, Gerace KV, Roland RL, Chrzan BG. Estrogen regulation of apoptosis in osteoblasts. Physiol Behav. 2010;99 (2):181-5.

18. Yuan FL, Li X, Lu WG, Xu RS, Zhao YQ, Li CW, et al. Regulatory T cells as a potent target for controlling bone loss. Biochem Biophys Res Commun. 2010;402 (2) :173-6.

19. Boekholdt SM, Agema WR, Peters RJ, Zwinderman AH, van der Wall EE, Reitsma PH, et al. Variants of toll-like receptor 4 modify the efficacy of statin therapy and the risk of cardiovascular events. Circulation. 2003;107 (19) :2416-21.

20. Hollestelle SC, De Vries MR, Van Keulen JK, Schoneveld AH, Vink A, Strijder CF, et al. Toll-like receptor 4 is involved in outward arterial remodeling. Circulation. 2004;109 (3) :393-8.

21. Guo QS, Xia B, Jiang Y, Morre SA, Cheng L, Li J, et al. Polymorphisms of CD14 gene and TLR4 gene are not associated with ulcerative colitis in Chinese patients. Postgrad Med J. 2005;81 (958) :526-9.

22. Nakada TA, Hirasawa H, Oda S, Shiga H, Matsuda K, Nakamura $\mathrm{M}$, et al. Influence of toll-like receptor $4, \mathrm{CD} 14$, tumor necrosis factor, and interleukine-10 gene polymorphisms on clinical outcome in Japanese critically ill patients. J Surg Res. 2005;129 (2) :322-8.

23. Kim YS, Hwang YJ, Kim SY, Yang SM, Lee KY, Park Ie B. Rarity of TLR4 Asp299Gly and Thr399Ile polymorphisms in the Korean population. Yonsei Med J. 2008;49 (1) :58-62.

24. Santos JL, Lera L, Perez-Bravo F, Albala C. Adiposity and bone mineral density of Chilean elderly women in relation to tolllike receptor 4 gene polymorphisms. Ann Hum Biol. 2006;33 (56) :585-92.

25. Koh JM, Lee YS, Kim YS, Park SH, Lee SH, Kim HH, et al. Heat shock protein 60 causes osteoclastic bone resorption via tolllike receptor-2 in estrogen deficiency. Bone. 2009;45 (4) :65060.

26. Lorne E, Dupont H, Abraham E. Toll-like receptors 2 and 4: initiators of non-septic inflammation in critical care medicine? Intensive Care Med. 2010;36 (11) :1826-35.

27. Johnson GB, Riggs BL, Platt JL. A genetic basis for the "Adonis" phenotype of low adiposity and strong bones. FASEB J. 2004;18 (11) :1282-4.

28. Itoh K, Udagawa N, Kobayashi K, Suda K, Li X, Takami M, et al. Lipopolysaccharide promotes the survival of osteoclasts via Toll-like receptor 4 , but cytokine production of osteoclasts in response to lipopolysaccharide is different from that of macrophages. J Immunol. 2003;170 (7) :3688-95.

29. Montes A, Asensi V, Alvarez V, Valle E, Ocaña M, Meana A, et al. The Toll-like receptor 4 (Asp299Gly) polymorphism is a risk factor for Gram-negative and haematogenous osteomyelitis. Clin Exp Immunol. 2006;143 (3) :404-13. 